\title{
ANÁLISE COMPARATIVA E TRADUÇÃO SOB O VIÉS DA METALINGUÍSTICA DE BAKHTIN: COURS DE LINGUISTIQUE GÉNÉRALE NAS TRADUÇÕES AO RUSSO E AO PORTUGUÊS
}

\author{
Igor Bezerra de Mesquita 1 \\ Sheila Vieira de Camargo Grillo ${ }^{1}$ \\ ${ }^{1}$ Universidade de São Paulo, São Paulo, São Paulo, Brasil
}

\begin{abstract}
Resumo: O artigo objetiva demonstrar a tradução como ato criativo e cultural, ao analisar comparativamente trechos de Cours de Linguistique Générale [Curso de Linguística Geral] em suas traduções ao russo e ao português. Para tanto, a metalinguística bakhtiniana mostra-se fértil ao englobar fatores extralinguísticos à análise, a partir de conceitos como: enunciado, destinatário presumido, horizonte social, gênero. Além disso, proveniente da noção bakhtiniana de enunciado, o conceito de re-enunciado (tradução) trabalhado por Heber Silva (2018) contribui para elaborar nossa compreensão de tradução, que abarca as características do enunciado, especialmente a da interação discursiva como realidade do ato linguístico. Os resultados da análise evidenciaram como o contexto sócio-histórico e acadêmico dos respectivos países (Brasil da década de 1960/1970, com o início do desenvolvimento da disciplina Linguística na academia; União Soviética da década de 1930, com uma longa tradição acadêmica desde o século XIX) influenciam por dentro na composição e no estilo dos re-enunciados.
\end{abstract}

Palavras-chave: Tradução; Análise Comparativa; Bakhtin; Curso de Linguística Geral 


\title{
COMPARATIVE ANALYSIS AND TRANSLATION UNDER BAKHTIN'S METALINGUISTICS: COURS DE LINGUISTIQUE GÉNÉRALE ON THE RUSSIAN AND PORTUGUESE TRANSLATIONS
}

\begin{abstract}
The article aims to demonstrate how translation is a creative and cultural act by comparatively analyzing excerpts of Cours de Linguistique Générale [General Linguistics Course] in its Russian and Brazilian translations. To this end, Bakhtinian metalinguistics seems fruitful, since it includes extralinguistic factors to the analysis, from concepts like: utterance, presumed addressee, social purview, genre. Besides that, derived from Bakhtin's notion of utterance, the concept of re-utterance (translation) with which Heber Silva (2018) deals contributes to elaborate the understanding of translation - one that embraces the utterance characteristics, especially verbal interaction as the reality of the linguistic act. The results of the analysis showed the influence from the inside of the re-utterance composition and style caused by the social-historic and academic context of the respective countries (1960's/1970's Brazil, with the beginning of the development of Linguistics as a discipline in the academy; 1930's Soviet Union, with a long academic tradition since XIX century).
\end{abstract}

Keywords: Translation; Comparative Analysis; Bakhtin; General Linguistics Course

\section{A tradução para o russo e para o português do Cours de linguistique générale de Ferdinand de Saussure: objetivo, metodologia e contexto dos re-enunciados}

A tradução, como todo exercício intelectual humano, carrega em si as digitais e as decisões daquele que a realizou. A ideia de uma tradução despersonalizada e transparente, portanto, é inconcebível, bem como idealizada. Assim, objetiva-se aqui averiguar e analisar como esses traços se manifestam nas traduções ao russo e ao português de capítulos selecionados do Cours de Linguistique Générale ${ }^{l}$,

${ }^{1}$ Doravante $C L G$. 
sobretudo ao incluir o impacto causado também pelo entorno sócio -histórico (Brasil da década de 1960 e União Soviética da década de 1930), pelas tradições linguísticas de cada país e por características específicas das culturas acadêmicas, aspectos indissociáveis para uma compreensão apurada do ato singular e complexo, tal qual é todo ato linguístico.

É imprescindível que se exponha, para tanto, a metodologia de constituição do corpus, que leva em consideração como critérios para selecionar os capítulos a serem analisados 1) a presença de conceitos centrais para a delimitação da nova ciência proposta por Ferdinand de Saussure, assim como 2) os conceitos saussureanos mais discutidos ou conhecidos ${ }^{2}$ que são desenvolvidos nesses capítulos e também 3) a reivindicação do objeto da nova ciência, de sua metodologia e de seu caráter inovador diante dos estudos linguísticos realizados até então. A confluência desses três critérios resultou na delimitação de cinco capítulos: Introduction - Chap. 3. Objet de la linguistique, Chap. 4. Linguistique de la langue et linguistique de la parole; Partie 1 - Chap. 1 Nature du signe linguistique, Chap. 3 La linguistique statique et la linguistique évolutive; Partie 2 - Chap. 4 La valeur linguistique.

Ademais, os excertos escolhidos dos capítulos são aqueles considerados mais representativos das características de cada re-enunciado (Silva), ou seja, aqueles que apresentam os dados mais claramente observados ao longo de toda a análise, uma vez que o espaço do artigo não permite uma exposição completa de todos os trechos avaliados. De qualquer modo, procura-se, por conseguinte,

${ }^{2}$ Pode-se, por exemplo, observar as discussões do capítulo do manual "Introdução à Linguística I: Objetos Teóricos", especificamente dos capítulos "Teoria dos Signos" e "A língua como objeto da Linguística". No primeiro, há a apresentação de conceitos como Composição e Valor dos Signos, Arbitrariedade do Signo e A linearidade do Signo. No segundo, a das dicotomias Sincronia e Diacronia; Língua e Fala; Significante e Significado; Paradigma e Sintagma. (Fiorin, 5594) Além disso, quando observamos até mesmo a capa da edição brasileira do $C L G$, por exemplo, nela veem-se os conceitos mais famigerados do linguista suíço, comprovando como há determinada terminologia de seu pensamento que se cristalizou nos estudos linguísticos ocidentais. 
que, por sua anamnese, sejam mostrados as abordagens e o modus operandi de cada tradutor.

No que concerne à metodologia de análise, o conceito de tertium comparationis (Claudel et al, 2013) é muito profícuo ao estabelecer um ponto de apoio - o original francês e o gênero dos enunciados - para mediar e assentar solidamente o aspecto comparativo da análise. A definição de re-enunciado e as categorias de expansão, reacentuação e condensação terminológica (Silva, 2018) também se mostram pertinentes a ela. Além disso, em virtude da visão sociológica, que traz como elemento constituinte da tradução as interações e inter-relações sociais e históricas ao âmbito discursivo, a teoria bakhtiniana de enunciado (Bakhtin, 2011 [1959-61]; Volóchinov, 2018 [1929]) serve como força motriz à análise. Nessa teoria, a inclusão não só dos fatores linguísticos, mas também extralinguísticos (autor, data de publicação, formação dos autores, contexto histórico e intelectual, diálogo com outros enunciados etc.) entram no escopo da análise. Assim, faz-se necessária a inclusão resumida nessa seção desses elementos para norteá-la:

A tradução russa é de 1933 e foi publicada pela editora soviétiса, ОГИЗ (Объединение государственных книжно-журнальных издательств [“União das editoras estatais literária-jornalísticas”]), pelo selo Соцэкгиз (социально-экономическое ["social-econômico"]) que viria a lançar textos de importantes autores, como os historiadores Solovióv, Kliutchévski, Uspiénski; os filósofos Florénski, Lósev etc. O CLG pertence à série de livros intitulada Языковеды Запада [“Estudos Linguísticos do Ocidente”], dentro da qual ele é o primeiro lançamento.

A edição russa vem com a tradução direta do francês por Alieksêi Sukhótin (1888-1942), tradutor e linguista formado no Московский институт востоковедения [“Instituto Moscovita de Estudos Orientais”], que participou da Escola russa de fonologia, surgida a partir dos estudos sobre o fonema desenvolvidos por Baudouin de Courtenay, este considerado como um dos responsáveis juntamente com Saussure por prenunciar elementos da corrente linguística estruturalista. Em 1933, Sukhótin tornou-se professor 
no Московский городской педагогический институт [“Instituto Municipal Pedagógico de Moscou”], ocupando a cátedra de língua russa. A atuação de Sukhótin revela seu conhecimento das questões que rondavam a linguística à época e sobre as quais versava o $C L G$, algo que pode ter potencializado uma tradução atenta à precisão conceitual e terminológica.

Rozália Chor (1894-1939), importante linguista e estudiosa da história da literatura, formada na Второй Московский государственный университет ["Segunda Universidade Estatal de Moscou"], professora de 1928 a 1930 da Universidade Estatal do Azerbaijão e chefe do departamento de estudos linguísti$\cos$ na Московский государственный педагогический институт иностранных языков (Instituto Estatal Moscovita de Pedagogia de Línguas Estrangeiras). Chor ficou encarregada da revisão e das notas e foi ela quem concebeu a criação da série "Estudos Linguísticos Ocidentais" na qual a tradução do Curso foi lançada.

A tradução é precedida por um artigo introdutório de Dmitri Vvedénski (1890-1986), professor a partir de 1945 nа Московский педагогический государственный институт [“Instituto Estatal de Pedagogia de Moscou], onde se dedicava à pesquisa da língua e do estilo da literatura russa dos séculos XIX-XX. Seu artigo é intitulado Фердинанд де-Соссюр и его место в лингвистике ["Ferdinand de Saussure e seu lugar na linguística"], no qual se traça um panorama acerca do estatuto das teorias linguísticas de Saussure.

Agora, quando vamos à edição brasileira, o que observamos é uma conjuntura diferente. A tradução é datada de 1969, coeditada pela Cultrix e pela Editora da Universidade de São Paulo, período em que os estudos linguísticos e filológicos brasileiros desenvolveram-se exponencialmente. A edição brasileira também vem com tradução direta do francês, mas empenhada por três pessoas, a saber: Antônio Chelini, professor de latim na Universidade de São Paulo graduado em Letras Clássicas na mesma faculdade; José Paulo Paes (1926-1998), poeta, tradutor e crítico literário, que colaborou, dentre vários, com os jornais da Folha de S. Paulo e $O$ Estado de $S$. Paulo, tendo iniciado seu trabalho na Editora Cultrix em 1963 e 
sendo conhecido, principalmente a partir de 1981, pelas suas traduções literárias; e Izidoro Blikstein, graduado em Letras Clássicas em 1960 pela Universidade de São Paulo e com mestrado em Linguística Comparativa em 1962 pela Université Lumière Lyon 2. Atualmente é professor adjunto da Fundação Getúlio Vargas com experiência na área da comunicação e dedica-se à Semiótica e Intertextualidade.

Há, similarmente à edição russa, um aparato que antecipa propriamente a tradução, intitulado "Prefácio à edição brasileira", escrito por Isaac Nicolau Salum (1913-1993), professor de línguas, bacharelado em 1940 em Teologia pela Faculdade de Teologia da Igreja Presbiteriana Independente do Brasil e licenciado em Letras Clássicas e Português pela Universidade de São Paulo, onde foi professor titular de filologia românica do Departamento de Letras. Salum teve forte e profícua produção científica nas áreas de linguística e filologia.

\section{Uma abordagem metalinguística ${ }^{3}$ da tradução}

A tradução será aqui concebida como um enunciado composto por aspectos linguísticos e extralinguísticos: ao se dizer algo, sempre se diz a um outro (destinatário real ou presumido), sob certas circunstâncias (meio social circundante e horizonte ideológico), por meio de certos recursos (escolha vocabular, construção sintática, entonação, gestos, expressões faciais etc.). Logo, já se imbuindo dos aspectos dialógicos da noção bakhtiniana de enunciado - "O enunciado (produção do discurso) como um todo individual, singular e historicamente único." (Bakhtin, 2011 [1959-61], p. 334, grifos nossos) -, o texto original é um todo único em seu caráter histórico, que aciona um interlocutor presumido (também chamado de dimensão pragmática da tradução), um contexto socioeconômi-

${ }^{3}$ Metalinguística é o termo empregado por Mikhail Bakhtin para fundar uma disciplina que toma a palavra, a linguagem, o discurso em suas dimensões linguística e extralinguística. Não confundir com a função metalinguística proposta pelo também pensador russo Roman Jakobson.

Cad. Trad., Florianópolis, v. 41, no 2 p. 400-427, mai-ago, 2021. 
co específico e uma determinada localização no fluxo da comunicação discursiva, pressupondo, assim, um antes e um depois - isto é, nunca se trata da primeira nem da última palavra dita acerca de tal referente ou objeto do sentido. O enunciado é então "um ato bilateral [...] determinado tanto por aquele de quem [ele] procede quanto por aquele para quem se dirige." (Volóchinov, 205).

Ao considerarmos que a tradução envolve sobretudo a relação entre dois enunciados, que compreendem não só aspectos singulares, mas também "relativamente estáveis" dos gêneros (Bakhtin, Os gê neros do discurso, 12), a tarefa do tradutor envolve o conhecimento e a compreensão das normas específicas dos gêneros do discurso, formados por construção composicional, estilo e conteúdo temático, que concretizam o projeto de dizer, a arquitetônica do autor. ${ }^{4}$

Dessa maneira, tendo o enunciado na língua de partida essas características, o enunciado na língua de chegada também as trará em si; daí o tradutor e estudioso da tradução Heber de Oliveira Costa e Silva apresentar a tradução como um re-enunciado ${ }^{5}$, possuidor das mesmas características do enunciado bakhtiniano, ao defini-la como:

\begin{abstract}
Primeiro, [...] uma re-enunciação (retomada-modificação) interlingual, que não pode jamais ser neutra. Segundo, afirmamos que no texto traduzido se manifesta uma voz enunciativa - a voz do tradutor - que está em diálogo com a voz do autor e outras vozes evocadas pelo texto (razão pela qual o tradutor não pode ser 'invisível'), trazendo em si pontos de vista e posições axiológicas de quem re-enuncia sobre o que é re-enunciado. Terceiro, a partir das propriedades dialógicas do enunciado, concluímos que cada tradução é única, pois é situada pelo conjunto do contexto e dos in-
\end{abstract}

\footnotetext{
${ }^{4}$ Em algumas correntes dos estudos da tradução, a consideração do gênero do discurso é chamada de "equivalência textual-normativa", conforme exposto por Minchin (2018) ao analisar a obra de Koller.

${ }^{5}$ Importante dizer que Heber não cunhou este conceito, uma vez que ele elabora seu pensamento a partir dos estudiosos Brian Mossop (Mossop, 1983) e Barbara Folkart (Folkart, 1991).
} 
terlocutores a quem é endereçada (compreensão responsiva ativa). (Silva, 90).

É essencial que se compreenda, em vista disso, a tradução nessa sua chave dialógica, em que não há espaço para encará-la como uma reprodução do enunciado-fonte, mas sim como a criação pelo tradutor de uma equivalência, conforme propõe Minchin (2018) a partir da leitura da obra de Koller, entre os enunciados de duas línguas/culturas distintas - a de origem e a de destino - uma vez que "as unidades da comunicação discursiva - enunciados totais - são irreprodutíveis" (Bakhtin, 2011 [1959-61], p. 335). Perde-se assim uma certa sacralidade que se tem sobre os enunciados de origem, ao quebrar com a hierarquia que vê a tradução como reprodução e impede que ela seja vista como criação; esta que, na verdade, é condição sine qua non do processo tradutológico, já que o re-enunciado deve conversar com as vozes contemporâneas ${ }^{6}$, além, é claro, daquelas que ressoavam em consonância ou dissonância quando da existência do enunciado original, extemporâneas. Em outros termos, considerando, assim como Minchin (2018), que a noção de equivalência entre o enunciado fonte e o enunciado traduzido não deve ser abandonada por completo, mas antes reinterpretada, compreendemos que o processo de tradução envolve uma relação tensa entre compreender, recuperar o enunciado fonte e produzir um novo enunciado na língua de chegada, considerando sua dimensão linguística e extralinguística. Daí, e noção de re-enunciado, um novo enunciado, que, contudo, mantém um vínculo indissociável com o enunciado da língua/cultura de partida.

\footnotetext{
${ }^{6}$ No domínio das ciências humanas, o diálogo com as vozes contemporâneas deve lidar com aspectos interculturais, que vão dos mais aos menos perceptíveis, a saber: símbolos, heróis, rituais e valores, (Pfau, Humblé). A partir de um estudo de caso, Pfau e Humblé defendem que o tradutor de artigos científicos de ciências humanas deve interferir no texto fonte (com a anuência do autor), a fim de adaptálo ao leitor estrangeiro, não necessariamente presumido pelo(s) autor(es) do texto fonte, considerando as suas diferenças interculturais e funcionando como um último parecerista/avaliador do artigo.
} 
Ao recriar um enunciado de uma outra cultura e tempo, o tradutor cria novos "modos de existência, novos sujeitos" (Bastos, 59), cuja determinação orienta-se pela busca daqueles elementos componentes de uma unidade dos espíritos, das culturas humanas, por meio do diálogo entre mundos diversos, mas com um fundo comum. Em outros termos, a intervenção do tradutor cria o terreno comum entre as culturas e os homens ao mesmo tempo que ressalta as singularidades, as multiplicidades, a polifonia da experiência humana, sempre andando "no fio da navalha do equívoco" (Bastos, 61)

Pensando nesse viés analítico-comparativo, por se tratar de dois re-enunciados, o conceito de tertium comparationis (Claudel et $a l$.), ou elemento de comparação, do grupo de pesquisadores franceses CLESTHIA axe sens et discours, é produtivo não só por seu caráter complementar, mas também por ir ao encontro da teoria bakhtiniana. O "ponto de semelhança" erigido por esse conceito é sustentador de um trabalho comparativo como o de traduções de um mesmo texto, visto que o tertium comparationis estabelece a base comum a partir da qual emergirão as diferenças e semelhanças. Daí a preferência pela expressão "ponto de semelhança" e não "ponto de igualdade"; nuance perfeitamente em acordo com a noção de enunciado em seu caráter único e irreprodutível, uma vez que o texto-fonte serve de base para a análise comparativa e não de espelho por cujo reflexo os re-enunciados devem ser idênticos.

Não obstante, na análise dos capítulos do CLG, ao mesmo tempo que o texto-fonte é o tertium comparationis, o gênero discursivo (ou equivalência textual-normativa) também desempenha função crucial no que diz respeito à compreensão do formato e composição de dado enunciado, haja vista que "a concepção da forma de um enunciado integral, isto é, de um determinado gênero do discurso, guia-nos no processo do nosso discurso" (Bakhtin, 2011 [195961], p. 286). Portanto, esse dado nos auxiliará na compreensão de como ambos os re-enunciados se organizaram e se compuseram.

Dito isso, é relevante as categorias estabelecidas por Heber Silva (135-136) de expansão, condensação terminológica e rea- 
centuação, pois servem plenamente para auxiliar na descrição e análise de vários elementos estilísticos dos enunciados traduzidos, ao evidenciarem a recorrência de decisões tradutórias nas edições russa e brasileira. Como será desenvolvido, a lapidação de termos mais adequados para expressão das ideias do enunciado-fonte, sujeita a exclusões, modificações, esclarecimentos e rearranjos, encaixam-se perfeitamente nessas categorias.

Assim, a necessidade que um tradutor vê de explicitar determinado termo ou trecho do original com a inserção de explicações que não se encontram no texto-fonte, localizadas geralmente em apostos no texto-alvo (expansão); a tentativa de conciliar com a tradução a terminologia utilizada pelo autor, por meio de uma "uniformização" que mantenha um padrão consistente de termos (condensação terminológica) e a escolha deliberada pelo tradutor por uma mudança de tom ou ênfase de uma sentença, exclusão de metáforas, modalização de verbos, sempre em relação ao original (reacentuação), são categorias profícuas numa análise entre traduções, sobretudo de textos científicos, que foram adotadas por nós nesta análise.

É importante, no entanto, destacar que, na observância do modo como se organizam os enunciados russo e brasileiro em relação ao original francês, em meio a suas divergências e convergências e de possíveis alterações de sentido no processo de "adequação" vocabular, interessa-nos analisar e refletir os motivos que provocaram tais fenômenos.

\section{Curso de Linguística Geral e Kurs óbschei lingvístiki: seus aspectos de constituição como re-enunciados}

\section{1. O destinatário-presumido e seu caráter formulador dos re-enunciados}

Um fator que é perceptível na leitura analítica das traduções é como os destinatários presumidos manifestam-se no modo como se 
organizam os re-enunciados. Os trechos apresentados abaixo são elucidativos:

\section{Tabela 1:}

\begin{tabular}{|c|c|c|}
\hline Original & Português & Russo \\
\hline $\begin{array}{l}\text { Ainsi en allemand } \\
\text { Sprache veut dire } \\
\text { «langue» et «langage»; } \\
\text { Rede correspond à peu } \\
\text { près à «parole», mais } \\
\text { y ajoute le sens spécial } \\
\text { de «discours». En latin } \\
\text { sermo signifie plutôt } \\
\text { «langage» et «parole», } \\
\text { tandis que lingua } \\
\text { désigne la langue, et } \\
\text { ainsi de suite. [...] c'est } \\
\text { une mauvaise méthode } \\
\text { que de partir des mots } \\
\text { pour définir les choses. }\end{array}$ & $\begin{array}{l}\text { Assim, em alemão, } \\
\text { Sprache quer dizer } \\
\text { "língua" e "linguagem"; } \\
\text { Rede corresponde } \\
\text { aproximadamente } \\
\text { a "palavra", mas } \\
\text { acrescentando-lhe } \\
\text { o sentido especial } \\
\text { de "discurso". Em } \\
\text { latim, sermo significa } \\
\text { antes "linguagem" e } \\
\text { "fala", enquanto lingua } \\
\text { significa a língua, e } \\
\text { assim por diante. [...] é } \\
\text { um mau método partir } \\
\text { dos termos para definir } \\
\text { as coisas. }\end{array}$ & $\begin{array}{l}\text { Так немецкое } \\
\text { “Sprache” } \\
\text { соответствует } \\
\text { французскому “langue” } \\
\text { и “langage”; "Rede” } \\
\text { - приблизительно } \\
\text { французскому } \\
\text { “раrole”, с добовочным } \\
\text { созначением } \\
\text { “ораторской речи” } \\
\text { (discours); латинское } \\
\text { “sermo" означает } \\
\text { скорее и “langage” } \\
\text { и “раrole”, тогда } \\
\text { как “lingua” значит } \\
\text { “язык” (languе) и т. д. } \\
\text { [...] плохо, когда при } \\
\text { определении вещей } \\
\text { исходят из слов. } \\
\text { (Saussure, Kurs óbschei } \\
\text { lingvístiki, 38) }\end{array}$ \\
\hline
\end{tabular}

Fonte: Elaboração própria.

Já é evidente como o pertencimento do tertium comparationis à mesma família linguística de um dos elementos comparativos (texto em português) facilita a tradução com termos mais "literais", enquanto o não pertencimento à mesma família linguística e a distância entre as famílias do outro elemento comparativo (texto em russo) obriga o tradutor a recorrer a estratégias variadas para contorno desse dilema. Isso não necessariamente representa uma incapacidade do profissional em traduzir da maneira mais precisa determinado vocábulo, mas sim demonstra o processo criativo da tradução 
e mesmo do estabelecimento de uma terminologia, pois o $C L G$ já era conhecido na Rússia antes de sua tradução e muitos de seus conceitos já estavam em pauta nos debates científicos anteriores à sua publicação ${ }^{7}$. Pode-se compreender, então, o porquê de alguns trechos veicularem entre parênteses até mesmo a terminologia do original, como visto no excerto acima e em outros como: "Ho что же такое язык? По нашему мнению, понятие языка (langue) не совпадает с понятием речевой деятельности вообе (langage)"8 A edição brasileira não tem essa problemática tão urgente, como visível no excerto acima e em outros, como: "Mas o que é a língua? Para nós, ela não se confunde com a linguagem" (Saussure, Curso de linguística geral, 17); indubitavelmente pelas correspondências simétricas dos termos em francês aos termos em português (langage-linguagem, langue-língua, parole-fala). Porém, assim como na Rússia, a terminologia dos conceitos saussureanos já era conhecida pelos estudos linguísticos brasileiros que se desenvolviam em meados dos anos $1960^{9}$ - época da publicação da tradução de $C L G$ no Brasil -, não isentando a edição brasileira de passagens como essa: "nós a chamaremos fala (parole)" (Saussure, Curso de linguística geral, 21). O que difere, porém, é a recorrência com que o recurso do original entre parênteses é empregado, tanto que a edição brasileira não viu a necessidade de alguma nota

${ }^{7}$ Lembramos a conhecida discussão no livro Marxismo e filosofia da linguagem. Problemas fundamentais do método sociológico na ciência da linguagem, em que Saussure é citado como o melhor representante do objetivismo abstrato ainda em 1929, ou seja, quatro anos antes da tradução do CLG.

${ }^{8}$ Saussure, Kurs óbschei lingvístiki, 34.

${ }^{9}$ Isso é comentado brevemente no artigo de Heitor Megale e César Nardelli Cambraia, que trata do desenvolvimento dos estudos filológicos no Brasil. Em um determinado trecho, discutindo sobre a ausência da disciplina Filologia em muitas instituições, é afirmado: "Esse vazio deixado por sua ausência [a Filologia na grade curricular do ensino superior], conforme atesta a pesquisadora, está diretamente relacionado ao fato de, a partir da década de sessenta, os estudos de língua portuguesa terem passado a privilegiar acentuadamente os aspectos descritivos sincrônicos, um dos escopos da Lingüística no Brasil. " (Megale, H.; Cambraia, C. N., 3, grifos nossos)

Cad. Trad., Florianópolis, v. 41, no 2 p. 400-427, mai-ago, 2021. 
de rodapé explicativa que destrinchasse os desafios de tradução. No caso do enunciado russo, essa discussão está não somente no texto saussureano em $\mathrm{si}^{10}$, mas também em nota de rodapé, na qual o tradutor Sukhótin expõe a complexidade de transmitir esses conceitos em função da ausência de vocábulos russos que comportem a semântica do original francês, ele explica então:

\begin{abstract}
$\mathrm{Na}$ presente tradução, langue será traduzido sempre como 'язык' ['língua'], parole como 'речь' ['discurso', 'fala']; langage, de acordo com uso no francês e com as terminologias de Saussure, que possibilita o entendimento tanto de 'язык' quanto de 'речь', é traduzido como uma dessas palavras russas, a depender do contexto, sendo mais frequente, porém, especialmente em todos aqueles casos em que se opõem langue e parole e em que langage atua como termo específico, convenientemente traduzir como 'речевая деятельность' ['atividade discursiva']. ${ }^{11}$ (Saussure, Kurs óbschei lingvístiki, 39, tradução nossa)
\end{abstract}

Essa nota desvela ao leitor a criatividade linguística do tradutor para melhor adequação e transmissão do sentido do original; usando a terminologia de Heber, aqui se indica o procedimento de condensação terminológica. Lida-se com a dificuldade da corres-

10 "Cumpre notar que definimos as coisas e não os termos; as distinções estabelecidas nada têm a recear, portanto, de certos termos ambíguos, que não têm correspondências entre duas línguas." (Saussure, Curso de linguística geral, 22) No original: "Il est à remarquer que nous avons défini des choses et non des mots; les distinctions établies n'ont donc rien à redouter de certains termes ambigus que ne se recouvrent pas d'une langue à l'autre" (Saussure, Cours de linguistique générale, 31).

${ }^{11}$ No original: “В настоящем переводе langue передается всегда через 'язык', parole - через 'речь', langage, согласно французскому словоупотреблению и терминологии Соссюра, покрывающее понятия и 'язык' и 'речь', переводится нами то одним, то другим из этих двух русских слов, в зависимости от контекста, чаще же всего, в особенности во всех тех случаях, когда оно, противопоставляясь langue и parole, выступает как термин, условно через 'речевая деятельность'.” (Saussure, Kurs óbschei lingvístiki, 39) 
pondência da terminologia do original também com o procedimento da expansão, como pode ser visto aqui:

\section{Tabela 2:}

\begin{tabular}{|l|l|l|}
\hline Original & Português & Russo \\
\hline $\begin{array}{l}\text { Enfin, c'est la parole } \\
\text { qui fait évoluer la } \\
\text { langue... (Saussure, } \\
\begin{array}{l}\text { Cours de linguistique } \\
\text { générale, 37) }\end{array}\end{array}$ & $\begin{array}{l}\text { Enfim, é a fala que } \\
\text { faz evoluir a língua... } \\
\text { (Saussure, Curso de } \\
\text { linguística geral, 27, } \\
\text { grifo nosso) }\end{array}$ & $\begin{array}{l}\text { Наконец, явлениями } \\
\text { речи обусловлена } \\
\text { эволюция языка... } \\
\text { [Enfim, dos fenômenos } \\
\text { da fala determina-se } \\
\text { a evolução da língua] } \\
\text { (Saussure, Kurs óbschei } \\
\text { lingvístiki, 42, grifo } \\
\text { nosso) }\end{array}$ \\
\hline
\end{tabular}

Fonte: Elaboração própria

Não só se desloca a "fala" da função de sujeito para a de adjunto adnominal, como ela se encontra no interior de um adjunto adverbial. Assim, a oração "a fala que faz evoluir a língua" tornase "dos fenômenos da fala determina-se a evolução da língua". Demonstra-se como o tradutor Sukhótin expandiu a expressão do original, a fim de transpor o mais precisamente possível seu sentido, contornando a assimetria terminológica existente entre francês e russo - problemática que ele conhecia bem, em virtude de seu pertencimento a uma escola linguística debruçada sobre questões de uma linguística que viria a ser denominada estruturalista ${ }^{12}$. Ademais, é possível observar aqui, a partir da utilização da palavra russa "fenômenos", o que Pfau e Humblé afirmam sobre o aspecto intercultural com que o tradutor deve trabalhar, haja vista que essa palavra não se encontra no enunciado original - tanto é que não aparece na tradução brasileira -, mas indica a forte influência do pensamento acadêmico alemão sobre a academia russa, algo que será desenvolvido mais adiante.

12 Também é interessante saber que já havia a reflexão sobre a tradução da terminologia do $C L G$ para o russo. Conferir: Čudakova M. O.; Toddes E. A., 63-91. 
Retomando a categoria de condensação terminológica, na edição brasileira ela se dá de modo menos trabalhoso, por conta da facilidade na transposição da terminologia do original à língua portuguesa e, além disso, pela proposta divergente de cada edição, perceptível após análise de seus respectivos paratextos, pois no artigo introdutório da edição russa já fica claro que a tradução se destina aos especialistas da língua, enquanto a brasileira afirma grande interesse no público leigo ou entusiastas dos estudos linguísticos. Apesar de essa informação aparecer nos paratextos (afinal, as notas são inclusas neles), no próprio re-enunciado ela se mostra, como nesse outro exemplo:

\section{Tabela 3:}

\begin{tabular}{|c|c|c|}
\hline Original & Português & Russo \\
\hline $\begin{array}{l}\text { nous avons du } \\
\text { même coup situé la } \\
\text { linguistique tout entière. }\end{array}$ & $\begin{array}{l}\text { situamos ao mesmo } \\
\text { tempo toda a } \\
\text { Linguística. } \\
\text { (Saussure, Curso de } \\
\text { linguística geral, 26) }\end{array}$ & $\begin{array}{l}\text { мы тем самым } \\
\text { набросали схему всей } \\
\text { лингвистики [nós por } \\
\text { sua vez esboçamos } \\
\text { o esquema de toda } \\
\text { linguística]. (Saussure, } \\
\text { Kurs óbschei lingvístiki, } \\
41 \text { ) }\end{array}$ \\
\hline
\end{tabular}

Fonte: Elaboração própria

Como era de se esperar, a tradução brasileira aproxima-se muito do original, sendo isso percebido pela transformação de "tout entière" ["por inteiro, como um todo"] por "toda", anteposta à "Linguística”, que vem com letra maiúscula, designando mais delineadamente seu caráter de nova área do saber ${ }^{13}$. Na tradução russa, o que vemos é uma interpretação com nuances distintas do original, visí-

${ }^{13}$ Isso também é observável nos últimos parágrafos: "Pode-se, a rigor, conservar o nome de Linguística para cada uma dessas duas disciplinas e falar duma Linguística da fala. Será, porém, necessário não confundi-la com a Linguística propriamente dita, aquela cujo único objeto é a língua." (Saussure, Curso de linguística geral, 28, grifo meu) 
veis pelo verbo "набросали" [“esboçamos, contornamos”] no lugar de "avons situé" ["situamos"], por “тем самым" ["por sua vez, portanto"] no lugar de "du même coup" ["ao mesmo tempo, de uma vez”] e do acréscimo de “схема всей лингвистики” [“esquema da linguística inteira”]. Torna-se perceptível como o re-enunciado russo modula o sentido do original, aplicando uma noção não categórica e não imperativa, por conta de palavras indicadoras de um estudo preliminar: esboçar, esquematizar.

Esse maior zelo da edição russa quanto às afirmações do texto indica um posicionamento de proposição, isto é, o tradutor infiltra uma leitura de que as discussões conduzidas no $C L G$ não se põem como leis gerais, mas como reflexões e proposições que se encadeiam por meio do raciocínio do discurso construído pelos redatores do texto fonte. Fica deveras evidente quando no mesmo parágrafo se segue a frase "Все остальные элементы речевой деятельности, образующие по нашей терминологии 'речь'," "[Todos os elementos remanescentes da linguagem, que formam pela nossa terminologia 'a fala',]”, pois o termo acessório "pela nossa terminologia" inexiste no tertium comparationis. Isso, então, lastreia o zelo comentado no início desse parágrafo, deixando sempre claro ao leitor de que se trata de conceitos cujos nomes propõem um pensamento. Além do mais, não se pode relegar que há também um resguardo por parte do tradutor de sublinhar que naquele momento a palavra está em seu sentido terminológico, ênfase compreensível pela dificuldade da equivalência entre os termos originais (fator previamente já abordado).

De qualquer modo, uma língua, em meio a sua riqueza, sempre obtém, por intermédio de sua diversidade, recursos para exprimir e recriar determinado sentido. Assim, a tradução russa não é um antro de obstáculos a serem ultrapassados e de precipícios com os quais o tradutor deve acautelar-se; é também o espaço em que é possível recriar com beleza e precisão o sentido do enunciado fonte. Por exemplo: 


\section{Tabela 4:}

\begin{tabular}{|c|c|c|}
\hline Original & Português & Russo \\
\hline $\begin{array}{l}\text { En paléoslave slovo, } \\
\text { «mot», fait à l'instrum. } \\
\text { sg. slovemb au nom. pl. } \\
\text { slova, au gén. pl. slovb } \\
\text { [...] Mais aujourd'hui } \\
\text { les voyelles «faibles» } \\
\text { ь et ๖, représentants } \\
\text { slaves de i et u indo- } \\
\text { européen, ont disparu; } \\
\text { d'où en tchèque, par } \\
\text { exemple, slovo, slovem, } \\
\text { slova, slov; [...] }\end{array}$ & $\begin{array}{l}\text { Em páleo-eslavo } \\
\text { slovo, "palavra", faz, } \\
\text { no caso instrumental } \\
\text { singular, slovemb, no } \\
\text { nominativo plural slova, } \\
\text { no genitivo plural slovъ } \\
\text { etc. [...] Hoje, porém, } \\
\text { as vogais "fracas" ь е ъ } \\
\text {, representantes eslavas } \\
\text { de } i \text { e } u \text { indo-europeus, } \\
\text { desapareceram; daí em } \\
\text { tcheco, por exemplo, } \\
\text { slovo, slovem, slova, } \\
\text { slov; [...] }\end{array}$ & $\begin{array}{l}\text { В старославянском } \\
\text { яз. льто имеет в } \\
\text { твор. п. единств. } \\
\text { ч. льтот, в имен. п. } \\
\text { множ. ч. льта, в род. } \\
\text { п. множ. ч. льтъ и } \\
\text { т. д.; [...] Но ныне } \\
\text { “слабые” гласные } \\
\text { ь и ъ, славянские } \\
\text { представители } \\
\text { индоевропейских } \\
i \text { и } u, \text { исчезли; } \\
\text { вследствие этого } \\
\text { например в русском } \\
\text { яз. склоняется: лето, } \\
\text { летом, лета, лем [...] } \\
\text { [No eslavão antigo } \\
\text { льто possui no caso } \\
\text { instrumental singular } \\
\text { льтот, nо nominativo } \\
\text { plural льта, no } \\
\text { genitivo plural льть } \\
\text {, etc.; Mas, agora, as } \\
\text { vogais “fracas” ь е ъ } \\
\text {, representantes eslavas } \\
\text { do indo-еuropeu } i \text { е } u, \\
\text { desapareceram; devido } \\
\text { а isso, na língua russa, } \\
\text { рor exemplo, declina-se: } \\
\text { лето, летом, лета, лем } \\
\text { (Saussure, Kurs óbschei } \\
\text { lingvístiki, 93) }\end{array}$ \\
\hline
\end{tabular}

Fonte: Elaboração própria

Um re-enunciado não precisa montar todas as exatas estruturas linguísticas que se manifestam no original, em realidade, é até mesmo irrealizável. Muitas vezes uma reinterpretação que busque um sentido equivalente, angariando outras palavras e reformulan- 
do suas orações, mostra-se proveitosa para a tradução. Este é o conceito de reacentuação, que pode ser observado nos excertos acima, em que o original traz como exemplo slovo ["palavra"] do páleo-eslavo - hoje consagrado como eslavão antigo - e suas declinações, comparando então como a perda das vogais fracas ь е ъ еm outras línguas eslavas alterou as declinações da palavra no sistema linguístico tcheco. Entretanto, sendo o russo uma língua eslava, o tradutor tomou a liberdade de substituir o exemplo do eslavão antigo, utilizando a palavra лŁто ["verão"] е mostrando como a mesma palavra em russo e suas declinações foram impactados pela perda da vogal $\mathrm{b}$.

Assim, percebe-se como o tradutor não teve o simples papel de transpor impessoal e literalmente o que está no enunciado-fonte - houve a apreensão do argumento construído no original para, enfim, entregar um re-enunciado equivalente e até mais próximo ao destinatário falante de russo. Assim, houve um diálogo entre duas culturas, entre as duas realidades dos enunciados, mantendo e, simultaneamente, recriando sentidos.

A reacentuação também pode ser observada no re-enunciado brasileiro, como nesse excerto:

\section{Tabela 5:}

\begin{tabular}{|l|l|l|}
\hline Original & Português & Russo \\
\hline $\begin{array}{l}\text { La langue n'est pas une } \\
\text { fonction du sujet parlant } \\
\text { (Saussure, Cours de } \\
\text { linguistique générale, } \\
\text { 30) }\end{array}$ & $\begin{array}{l}\text { A língua não constitui, } \\
\text { pois, uma função do } \\
\text { falante (Saussure, Curso } \\
\text { de linguística geral, 22, } \\
\text { grifo nosso) }\end{array}$ & $\begin{array}{l}\text { Язык не есть функция } \\
\text { говоряего субъекта } \\
\text { lingvístiki, 38) }\end{array}$ \\
\hline
\end{tabular}

Fonte: Elaboração própria

Há o acréscimo no enunciado brasileiro da conjunção conclusiva "pois", que é inexistente no original - daí a motivação de permanecer inexistente na tradução ao russo: “A língua não é uma função do sujeito falante”. Em oposição ao caso anterior, aqui não se trata de um rearranjo interno de vocábulos, mas da adição de 
novos. A despeito disso, é nítido que a adição não inventou um sentido que não havia no original - explicitou-o, delineando seu tom de conclusibilidade. Esse excerto é antecedido por 4 itens que resumem as características argumentadas até então, impondo no parágrafo que fecha essa enumeração um sentido conclusivo.

Essas decisões que acrescentam sentidos, ou melhor, trá-los à superfície semântica da oração, visto que ao longo da leitura do texto o sentido conclusivo subterrâneo é perceptível, anunciam a presença viva de sujeitos que trabalharam e pensaram a redação desse re-enunciado. Assim, colocando lado a lado as traduções com seu texto fonte, seus contrastes projetam como semelhança um eu - ou eus - não corresponsável do enunciado, mas sim plenamente responsável por ele, pois nos é mostrado até mesmo os esquadros mentais que determinaram qual caminho seguido em cada tradução. Aquém disso, fica notável como a expressão e comunicação não se dão somente por aquilo graficamente escrito, mas, principalmente, pelas entrelinhas metalinguísticas (em sentido bakhtiniano) que se infiltram na nossa percepção e depreensão do enunciado.

\section{2 O gênero e a busca por objetividade do re-enunciado russo}

Conforme já levantado, o destinatário presumido norteia as traduções em sua composição e estruturação. Portanto, a edição brasileira, cujo público é falante de português e é mais amplo, apresenta um re-enunciado despreocupado com o esmiuçamento e aprofundamento das discussões linguísticas, além de não relatar possíveis obstáculos tradutológicos - este ponto compreensível ao se pensar na proximidade entre as línguas. No caso da edição russa, ocorre o oposto, visto que o público é mais restrito - especialistas e estudiosos da língua -, sendo apresentados muitos dados e discussões, especialmente no que diz respeito às decisões do tradutor. Além disso, um comportamento de neutralidade emana do re-enunciado como um todo, pois é observável a formalidade perpetrada por termos mais livrescos e pela exclusão de metáforas não 
cristalizadas na língua do original ${ }^{14}$. Exemplos de termos livrescos são "Нисколько" ["não, de jeito nenhum"], “либо” [“se”], “ибо" ["pois"], “прочий” [“outro"] “нечто" ["alguma coisa”] “ чересчур" ["demasiado"] to na edição brasileira não se diferenciam de palavras usuais no cotidiano das duas culturas românicas, ao contrário da russa, que naturalmente possui esses termos que indicam uma mudança de tom e formalidade de um discurso, que nesse caso é pertencente ao gênero científico. Por conta disso, metáforas mais incomuns entrariam em choque com esse aspecto discursivo do letramento russo. A respeito disso, vejamos:

\section{Tabela 6:}

\begin{tabular}{|c|c|c|}
\hline Original & Português & Russo \\
\hline $\begin{array}{l}\text { Pris dans son tout, le } \\
\text { langage est multiforme } \\
\text { et hétéroclite ; à cheval } \\
\text { sur plusieurs domaines, } \\
\text { [...] il ne se laisse classe } \\
\text { dans aucune catégorie } \\
\text { des fait humains, parce } \\
\text { qu'on ne sait comment } \\
\text { dégager son unité. }\end{array}$ & $\begin{array}{l}\text { Tomada em seu todo, a } \\
\text { linguagem é multiforme } \\
\text { e heteróclita; o cavaleiro } \\
\text { de diferentes domínios, } \\
\text { [...] não se deixa } \\
\text { classificar em nenhuma } \\
\text { categoria de fatos } \\
\text { humanos, pois não se } \\
\text { sabe como inferir sua } \\
\text { unidade. }\end{array}$ & $\begin{array}{l}\text { Взятая в целом, } \\
\text { речевая деятельность } \\
\text { многоформенна } \\
\text { и разносистемна; } \\
\text { вторгаясь в несколько } \\
\text { областей, [...] её } \\
\text { нельзя отнести ни к } \\
\text { одной из категорий } \\
\text { явлений человеческой } \\
\text { жизни, так как она сама } \\
\text { по себе не представляет } \\
\text { ничего единого. } \\
\text { [Tomada em seu todo, a } \\
\text { linguagem é multiforme } \\
\text { e heteróclita; invadindo }\end{array}$ \\
\hline
\end{tabular}

${ }^{14}$ A metáfora "estar longe de..." é usual aos falantes das duas línguas românicas estudadas aqui, daí a compreensão de que se trata de expressão cristalizada. Metáforas não cristalizadas, por conseguinte, são aquelas tiradas da criatividade do interactante do discurso, que não estabelecem precedentes linguísticos propícios à afirmação, em sentido saussureano, de que são fatos da língua, mas sim fatos da fala.

${ }^{15}$ Nas páginas 35-35 tem-se um punhado representativo dessas expressões livrescas. (Saussure, Kurs óbschei lingvístiki) 


\begin{tabular}{|c|c|c|}
\hline $\begin{array}{l}\text { (Saussure, Cours de } \\
\text { linguistique générale, } \\
\text { 25) }\end{array}$ & $\begin{array}{l}\text { (Saussure, Curso de } \\
\text { linguística geral, } 17, \\
\text { grifo nosso) }\end{array}$ & $\begin{array}{l}\text { vários campos, [...] não } \\
\text { se deve relacioná-la a } \\
\text { nenhuma das categorias } \\
\text { dos fenômenos da vida } \\
\text { humana, posto que ela } \\
\text { por si só não apresenta } \\
\text { uma unidade] (Saussure, } \\
\text { Kurs óbschei lingvístiki, } \\
\text { 34-35, grifo nosso) }\end{array}$ \\
\hline
\end{tabular}

Fonte: Elaboração própria

Há no original a metaforização da linguagem como "cheval sur plusieurs domaines", transposto ao português como "o cavaleiro de diferentes domínios". Os tradutores brasileiros optaram pela manutenção dessa expressão, decisão que pode ser compreensível ao se pensar que entre os tradutores está o poeta José Paulo Paes - muito provavelmente preocupado com um acabamento artístico do re-enunciado brasileiro. Agora, essa metáfora é sumariamente apagada no re-enunciado russo, que se constrói sob um prisma mais formal e objetivo, em consonância com a esfera científica e o gênero de tratado teórico: "Tomada no todo, a atividade linguageira [linguagem] é multiforme e heteróclita; invadindo vários campos". Além disso, talvez fosse uma metáfora pouco ressonante a um leitor russo, que talvez nela não visse muita função e a estranhasse em meio a um enunciado que é, como um todo, pouco imagético e poético. Assim, a linguagem heteróclita e multifacetada segue com a ideia: “вторгаясь в несколько областей" [“invadindo vários outros domínios"], que em certa medida mantém resquícios da metáfora original, embora a domestique para o leitor ao torná-la mais acordante com o léxico do domínio científico. Tanto é notável essa metáfora ser distante do público científico russo, que no momento em que há uma outra, a tradução russa resolve mantê-la, por ser uma que esteja mais próxima de um conhecimento de mundo mais irrestrito e por ter caráter mais simplista: “Язык - это клад” [“A língua é um tesouro”] (Saussure, Kurs óbschei lingvístiki, 38). 
A exclusão das metáforas é um procedimento muito recorrente, o que atesta como o gênero e o destinatário presumido influenciam por dentro a construção do enunciado, estabelecendo as balizas necessárias à sua (re)organização. Acrescentam-se mais exemplos apenas para fins de exposição dessa recorrência:

\section{Tabela 7:}

\begin{tabular}{|c|c|c|}
\hline Original & Português & Russo \\
\hline $\begin{array}{l}\text { l'individu a besoin d'em } \\
\text { apprentissage pour em } \\
\text { connaître le jeu } \\
\text { (Saussure, Cours de } \\
\text { linguistique générale, } \\
\text { 31, grifo nosso) }\end{array}$ & $\begin{array}{l}\text { o indivíduo tem } \\
\text { necessidade de } \\
\text { uma aprendizagem } \\
\text { para conhecer-lhe } \\
\text { o funcionamento } \\
\text { (Saussure, Curso de } \\
\text { linguística geral, 22) }\end{array}$ & $\begin{array}{l}\text { чтобы пользоваться } \\
\text { языком, индивид } \\
\text { должен ему научиться } \\
\text { [“para usar a língua, o } \\
\text { indivíduo deve aprendê- } \\
\text { la”] (Saussure, Kurs } \\
\text { óbschei lingvístiki, 39) }\end{array}$ \\
\hline $\begin{array}{l}\text { (Saussure, Cours de } \\
\text { linguistique générale, } \\
98, \text { grifos nossos) }\end{array}$ & $\begin{array}{l}\text { a representação que dele } \\
\text { nos dá o testemunho de } \\
\text { nossos sentidos }\end{array}$ & $\begin{array}{l}\text { представление, } \\
\text { получаемое нами о } \\
\text { нем посредстом наших } \\
\text { органов чувств [“а } \\
\text { representação dele que } \\
\text { é percebida por nós por } \\
\text { meio de nossos órgãos } \\
\text { sensoriais”] (Saussure, } \\
\text { Kurs óbschei lingvístiki, } \\
\text { 77-78, grifos nossos) } \\
\end{array}$ \\
\hline $\begin{array}{l}\text { le jeu de la langue } \\
\text { (Saussure, Cours de } \\
\text { linguistique générale, p. } \\
\text { 125, grifo nosso) }\end{array}$ & $\begin{array}{l}\text { o jogo da língua } \\
\text { (Saussure, Curso de } \\
\text { linguística geral, 104, } \\
\text { grifo nosso) }\end{array}$ & $\begin{array}{l}\text { механикой языка [“o } \\
\text { mecanismo da língua] } \\
\text { (Saussure, Kurs óbschei } \\
\text { lingvístiki, 93, grifo } \\
\text { nosso) }\end{array}$ \\
\hline $\begin{array}{l}\text { le germe de tous les } \\
\text { changements } \\
\text { (Saussure, Cours de } \\
\text { linguistique générale, } \\
138, \text { grifo nosso) }\end{array}$ & $\begin{array}{l}\text { o germe de todas as } \\
\text { modificações } \\
\text { (Saussure, Curso de } \\
\text { linguística geral, } 115, \\
\text { grifo nosso) }\end{array}$ & $\begin{array}{l}\text { источник всех } \\
\text { изменений [“a fonte de } \\
\text { todas as modificações”] } \\
\text { (Saussure, Kurs óbschei } \\
\text { lingvístiki, 102, grifo } \\
\text { nosso) }\end{array}$ \\
\hline
\end{tabular}

Fonte: Elaboração própria 
Uma hipótese para a eliminação das metáforas na tradução soviética pode ser a maior padronização do estilo científico naquele país, que é descrito como abstrato, generalizante, lógico e objetivo nas escolas funcionalistas (Glushkova \& Ferreira).

Por fim, retornando ao primeiro excerto da seção, é relevante notar o repertório de culturas de língua francesa e como elas influenciam a produção do discurso - ou como por intermédio dele se percebe sua influência -, é de suma importância observar as reverberações das culturas acadêmicas nos próprios termos utilizados. É o que se vê no segundo itálico dos trechos destacados, em que "faits humains" é traduzido ao português como "fatos humanos", mas ao russo como “явления человеческой жизни" ["fenômenos da vida humana"]. O termo original pode estabelecer alguma relação com o método sociológico de Durkheim ${ }^{16}$, no qual os fatos sociais se objetificam como coisas e ganham unidade para que se possa estudá-las na maior impessoalidade possível - daí o texto de Saussure apontar que a linguagem não é passível de uma categorização nos fatos humanos, já que essa unidade existente nos fatos sociais não se sustenta no caso dela. O re-enunciado russo, por sua vez, não traz a palavra fatos, mas sim fenômenos, o que vai ao encontro da retórica mais formal e neutra da tradução, mas que também denuncia o pano de fundo da ciência idealista alemã, que tanto impacto teve sobre a academia russa. ${ }^{17}$ A linguística alemã

\footnotetext{
${ }^{16}$ No artigo introdutório da edição russa, o autor Vvedenski aponta de maneira crítica a ressonância que Durkheim tem em muito do pensamento saussureano, sendo impossível negar que Saussure deve ter bebido do método sociológico durkheimiano.

${ }^{17} \mathrm{O}$ pensamento alemão como um todo foi tão importante na constituição das ciências russas que, em oposição ao Ocidente, que tem Saussure como o pai da linguística, na Rússia, é o linguista e filósofo Wilhelm von Humboldt considerado como precursor: "A influência do pensamento humboldtiano sobre as teorias da linguagem da Rússia e na União Soviética pode ser atestada por meio da leitura da obra Istória iazikóznania [História da linguística], de 2008, em que Humboldt é apontado como o fundador da linguística teórica, criador de um sistema da filosofia da linguagem no século XIX e precursor de quase todas as posições do Curso de Linguística Geral, de Ferdinand de Saussure." (Grillo, 18).
} 
não tinha a mesma perspectiva desenvolvida por Saussure, especialmente quanto aos indícios do método sociológico de Durkheim cujo apoio no desenvolvimento dos conceitos saussureanos é patente. Aquela enxerga um aspecto mais individualista e subjetivo no estudo da linguagem, não envolvendo a esfera social. Daí a veiculação direta e clara de "fato" no texto saussureano, referência pouco corrente na cultura acadêmica russa, na qual a palavra fenômeno proveniente dos estudos alemães ocupa maior espaço.

Além disso, Vvedenski (1933) afirma no artigo introdutório da edição russa que essa inclusão do social tanto na teoria saussureana quanto na teoria durkheimiana não passa de superficialidade, pois o aspecto social da luta de classes precisava ser incorporado no centro de uma teoria linguística para que o âmbito social fosse deveras avaliado, algo não realizado em nenhuma das correntes linguísticas até então do século XX, consideradas por ele burguesas. Identificamos aqui o reflexo evidente do marxismo soviético na interpretação e avaliação da obra saussureana.

\section{O que nos ensina uma análise comparativa de traduções sob o viés metalinguístico}

$\mathrm{O}$ ato tradutório é muito mais complexo e criativo do que uma transposição interlingual semântica, uma condução do sentido de um enunciado fonte a um enunciado de destino; é, mais do que isso, um verdadeiro diálogo que procura percorrer entre dois pontos - o sujeito que enuncia e seu interlocutor - um caminho de sentido que crie um re-enunciado do enunciado fonte. Não se deve, no entanto, afirmar que se trata do mesmo caminho, isto é, do mesmo enunciado, posto que os elementos responsáveis por construi-los são distintos - o tertium comparationis tem certo destinatário presumido e horizonte social, que são diferentes daqueles do re-enunciado russo e brasileiro. Essa distinção se intensifica ainda mais na medida em que a distância - temporal, histórica, socioeconômica, dos públicos - é 
acentuada: a edição russa é publicada 17 anos após a original, enquanto a brasileira após 54 anos.

Esses fatores desvelam como o ato tradutório envolve não apenas um campo puramente linguístico, mas também um que está além dele. A metalinguística bakhtiniana, então, mostra-se fundamental para apreensão e compreensão plenas dos aspectos estruturadores desses re-enunciados. Aliás, para o entendimento dos re-enunciados em si.

Fica claro, portanto, porque aparece no re-enunciado russo uma composição que se preocupa em evidenciar quais procedimentos culminaram em determinada condensação terminológica e que apresenta vocábulos e estruturas sintáticas mais diretos. Com um gênero e com um destinatário presumido tão bem estabelecidos como científicos, além de uma tradição linguística que vem desde o século XVIII, é compreensível deparar-se com essa organização do re-enunciado, que traz esses elementos como que por dentro. É relevante pensar, por exemplo, como o tradutor Aleksándr Sukhótin, que pertencia a um Círculo de linguistas que se dedicavam a estudos posteriormente designados como estruturalistas, se mostra influente na discussão da tradução mais apropriada dos termos saussureanos, bem como a exclusão de metáforas arrematam a busca por um discurso mais objetivo e abstrato e menos imagético assim, o alinhamento de todos esses fatores esclarecem a composição e o estilo do re-enunciado.

O mesmo pode ser observado no re-enunciado brasileiro, que é situado num contexto histórico e numa tradição acadêmica divergente: os anos 1960 no Brasil foram marcados pela criação dos primeiros cursos de pós-graduação em linguística o que justifica, por exemplo, o lançamento de uma tradução realizada por três pesquisadores, tendo apenas um deles uma formação mais sólida em linguística (um mestrado) - que, por sinal, foi obtido fora do país, deixando clara a inexistência de programas nacionais de pós-graduação em linguística. Ademais, esse re-enunciado é feito sem a pretensão de entregar uma edição crítica e científica a um público mais restrito, mas sim a de apresentar ao público geral o texto que 
consagrou o original ${ }^{18}$. Daí, em contraposição ao russo, não serem expostos os procedimentos tradutológicos do re-enunciado - sem desconsiderar, é claro, a proximidade entre as línguas românicas.

\section{Referências}

Bakhtin, M. Estética da criação verbal. Tradução de P. Bezerra. São Paulo: WMF Martins Fontes, 2011 [1959-61].

Bakhtin, M. Os gêneros do discurso. Tradução de P. Bezerra. São Paulo: Editora 34, 2016 [1952-3].

Bastos, L. T. C. "Morte do homem branco e potência-senzala: tradução em tempo de novas ontologias". Cadernos de Tradução, 39, n. especial, (2019): 47-64, Portal de Periódicos da UFSC. 20/01/2021. DOI: https://doi.org/10.5007/21757968.2019v39nespp47. Disponível em: https://periodicos.ufsc.br/index.php/ traducao/article/view/2175-7968.2019v39nespp47/42139.

Megale, H.; Cambraia, C. N. "Filologia portuguesa no Brasil". Delta. Documentação de Estudos em Linguística Teórica e Aplicada, 15, n. especial, (1999): 1-22. PUCSP.

Claudel, C.; von Münchow, P.; Ribeiro, M.P.; Pugnière-Saavedra, F.; TréguerFelten, G. "Langue, discours et culture : vingt ans de recherche en comparaison". Cultures, discours, langues, Claudel, C.; von Münchow, P.; Ribeiro, M.P.; Pugnière-Saavedra, F.; Tréguer-Felten, G. Condé-sur-Noireau : Lambert-Lucas, 2013. pp. 15-46.

18 “A edição a ser oferecida a um público mais amplo só pode ser a que consagrou a obra: a edição crítica, de leitura pesada, será obra de consulta de grande utilidade para os especialistas e para os mais aficionados" (Saussure, Curso de linguística geral, XXII). 
Čudakova, M. O.; Toddes, E. A. "Le première traduction russe du cours de linguistique générale de F. de Saussure et l'activité du Cercle Linguistique de Moscou”. Cahiers Ferdinand de Saussure. n 36, (1982) : 63-91.

Fiorin, J. L. (org.). Introdução à Linguística: I. Objetos teóricos. 6. ed. São Paulo: Contexto, 2015.

Folkart, B. Le Conflit des enunciations. Traduction et discours rapporté. Montréal: Éditions Balzac, 1991.

Grillo, S. V. C.. "Marxismo e filosofia da linguagem: uma resposta à ciência da linguagem do século XIX e início do XX". Marxismo e filosofia da linguagem. Problemas fundamentais do método sociológico na ciência da linguagem, Volóchinov, V. 2a. ed. São Paulo: Editora 34, 2018, v. 1, p. 7-79.

Glushkova, M.; Ferreira, R. B. "Análise comparativa estilística do gênero Resumo: um estudo de caso nas publicações científicas no Brasil e na Rússia”. Revista Linha D'Água, v. 31, (2018): 13-23.

Minchin, C. R. "A noção de equivalência de Köller: universalismo relativizado?”. Cadernos de tradução, 38, $\mathrm{n}^{0}$ : 3, (2018): 18-33, Portal de Periódicos da UFSC. 20/01/2021. DOI: https://doi.org/10.5007/2175-7968.2018v38n3p18. Disponível em: https://periodicos.ufsc.br/index.php/traducao/article/view/21757968.2018v38n3p18/37383.

Mossop, B. The translator as rapporteur: a concept for training and selfimprovement. Meta, 1983, v. 28, n. 3. p. 244-278. DOI: https://doi. org/10.7202/003674ar. Disponível em: https://www.erudit.org/fr/revues/ meta/1983-v28-n3-meta301/003674ar.pdf

Pfau, M.; Humblé, P. "Translation analysis of academic texts in the human sciences: a case study". Cadernos de tradução, 39, $\mathrm{n}^{\circ}$. 2, (2019): 146-165. Portal de Periódicos da UFSC. 20/01/2021. DOI: https://doi.org/10.5007/21757968.2019v39n2p146. Disponível em: https://periodicos.ufsc.br/index.php/ traducao/article/view/2175-7968.2019v39n2p146/40001. 
Silva, H. de O. C. e. A tradução na perspectiva dialógica: a re-enunciação da teoria de Austin em português. 2018. 203 f. Tese (Doutorado) - Curso de Letras, Centro de Artes e Educação, Universidade Federal de Pernambuco, Recife, 2018.

Saussure, F. de; Bailly, C.; Séchehaye, A. Cours de linguistique générale. Paris: Payot Et Rivages, 1995 [1916].

Saussure, F. de; Bailly, C.; Séchehaye, A. Kurs óbschei lingvístiki. Tradução de A. Sukhótin. Moscou: Etsegkiz, 1933 [1916].

Saussure, F. de; Bailly, C.; Séchehaye, A. Curso de linguística geral. Tradução de Antonio Chelini, José Paulo Paes e Izidoro Blikstein. São Paulo: Cultrix, 1969 [1916].

Vvedenski, D. Ferdinand de Saussure i ego miésto v lingvístike. In: Saussure, F. de; Bailly, C.; Séchehaye, A. Kurs óbschei lingvístiki. Tradução de A. Sukhótin. Moscou: Etsegkiz, 1933 [1916].

Volóchinov, V. Marxismo e filosofia da linguagem. Problemas fundamentais do método sociológico na ciência da linguagem. Tradução de S. Grillo e E. V. Américo. 2. ed. São Paulo: Editora 34, 2018 [1929].

Recebido em: 26/11/2020

Aceito em: 10/02/2021

Publicado em maio de 2021

Igor Bezerra de Mesquita. E-mail: mesquitaigorp@gmail.com. ORCID: https:// orcid.org/0000-0002-1894-0610.

Sheila Vieira de Camargo Grillo. E-mail: sheilagrillo@uol.com.br. ORCID: https://orcid.org/0000-0003-0480-2660. 